of the beam is low. Obviously, weak components are not observed if the density of the beam is sufficiently low; but it is misleading to write that they are "missed", since if weak components were to be investigated a beam of low density would not be used.

Prof. Tolansky gives a curve for the reflecting power of silver layers, from which he derives values of the reflecting power of the silvered surfaces of an etalon which imply a resolving power too low by a factor of more than two; for this reason I wrote that the "general superiority and greater scope of the [Fabry-Perot] etalon is rather understated". The space devoted by Prof. Tolansky to the Lummer plate is approximately half of the total space given to the etalon and compound etalon. This attaches too much relative importance to the Lurnmer plate; the results obtained with this instrument compared with those obtained with the etalon are in a very much smaller proportion. The passibilities of the double etalon are understated by Prof. Tolansky. The value of this instrument depends to a great extent on the ratio of the interferometer gaps which can be used, and he states that a ratio of $4: 1$ cannot be exceeded (quoting Meissner, 1941). A ratio of 10: 1 was used successfully in the examination of the resonance lines of lithium, in which intensity ratios of more than $10: 1$ are involved (Jackson and Kuhn, 1939) ; but Prof. Tolansky seems to have overlooked this.

With regard to the reflecting power of silvered surfaces, the contradictory measurements available to Prof. Tolansky were those of Strong, which give a reflecting power with red light of about 88 per cent when extrapolated for thick films, and those of Edwards and Petersen (Phys. Rev., 50, 871; 1936), which gave a value of 98 per cent under similar conditions. Prof. Tolansky has drawn curves (Figs. 7.8 and 7.12) and derived all his conclusions with regard to resolving power of the etalon from the lower of these figures; if he had also considered the higher figure he would have obtained alternative much higher values for the resolving power, and would have seen that Meissner's estimate of the maximum ratio of the gaps in the double etalon, calculated on the basis of a reflecting power of 80 per cent, would be inappropriate. Direct measurements of resolving power have been made at Oxford (and are to be published); the resolving power found for red light with a film with a transmission of 4 per cent requires a reflecting power of 93 per cent, which implies a value of at least 97 per cent for a thick silver layer, in good agreement with the figure given by Edwards and Petersen.

The photo-electric meter measures the transmission of the silver layer for light of any required colour; the resolving powers corresponding to various values of transmission, extending over a large range, have been determined experimentally. The reflecting power can be calculated from the resolving power. Measurement of reflectivity is not therefore an issue which is side-stepped. Furthermore, when the photo. electric method is used, mirrors are not 'selected' after preparation; the density of the silver layer is controlled during the evaporation, and a layer with the requisite degree of transmission is obtained.

Prof. Tolansky appears to agreo with my statement that evaporation has replaced sputtering (he "personally also uses only evaporation"); why then does he object to my criticizing him for devoting an approximately equal amount of space in his book to the two methods?
With regard to the mounting of the echelon grating, the aberration which Dr. Tolansky discusses cannot cause a loss of resolving power greater than 10 per cent except with objectives of shorter focal length than is permitted by the grain of the photographic plate; it was for this reason that I described a long discussion of this aberration as irrelevant. I might also have observed that another objection which Prof. Tolansky proposes (that the echelon might be curved and thus have focal properties) is not substantiated by experiment.

D. A. JACKSON

\section{Control of Atomic Energy}

THE article on the "Control of Atomic Energy" in Nature of November 15, p. 655, contains an important misstatement of fact that should not be allowed to pass without correction. It is stated: "The rejection by the Soviet Union of the very principles on which these proposals are based, including as they do the prohibition of atomic weapons, makes it difficult to see what further proposals can be advanced with any real hope of unanimous agreement",

This statement could only be taken to suggest that the Soviet Union has taken a stand against the prohibition of atomic weapons. In actual fact, the position is entirely different. Whatever may be the merits or demerits of the other parts of the Soviet plans on atomic energy control, the first point has always been the early conclusion of a convention to outlaw atomic weapons.

The first article of the proposed Convention, put forward by Mr. Gromyko as early as June 19, 1946, states: "The high contracting parties solemnly declare that they will forbid the production and use of a weapon based upon the use of atomic energy, and with this end in view, take upon themselves the following obligations: $(a)$ not to use, in any circumstances, an atomic weapon; $(b)$ to forbid the production and keeping of a weapon based upon the use of atomic energy ; (c) to destroy within a period of three months from the entry into force of this agreement all stocks of atomic energy weapons whether in a finished or semi-finished condition".

The American and British Governments have so far not been willing to agree to such a convention until agreement on the wider aspects of control have been achieved.

\section{E. H. S. Burhor}

(Hon. Secretary, Atomic Sciences Committee). Association of Scientific Workers,

15 Half Moon Street, London, W.1.

$\mathrm{WE}$ regret to find that the article referred to contains an ambiguous statement. What we had in mind was that, according to information generally available, proposals for the control of atomic energy which included the prohibition of atomic weapons had been rejected as a whole by the representative of the U.S.S.R. We had no intention of suggesting that the Soviet Union was opposed to the prohibition of atomic weapons, and we do not think the phrase used need necessarily bear that construction.EDIToRs. 